\title{
Knowledge, attitude and practice of breast self-examination in Khartoum State, Sudan
}

\author{
Authors: Senan Al-biatty, ${ }^{\mathrm{A}}$ Eiman Salih, ${ }^{\mathrm{A}}$ Sabha Alamin, ${ }^{\mathrm{A}}$ Nour Altoom, ${ }^{\mathrm{A}}$ Rayan Babeker ${ }^{\mathrm{A}}$ and Omnia Gnawi ${ }^{\mathrm{A}}$
}

\section{Introduction}

Globally, over 400,000 women die annually due to breast cancer. ${ }^{1}$ In Sudan, the National Cancer Registry showed that among all the cancer cases documented, breast cancer had an incidence of 25.1 per 100,000 per year. ${ }^{2}$ This high incidence is thought to be compounded by late presentation, particularly in Sudan. ${ }^{3}$

Research into breast self-examination (BSE) may help us better understand the patient pathway to presentation and its role in facilitating the early diagnosis of breast cancer. BSE is a practice that aims to positively influence early health seeking behaviour. ${ }^{4}$ Although many studies have detailed a link between BSE and early diagnosis of breast cancer, an equal number have failed to do so. ${ }^{5}$

This study was conducted from November 2016 to May 2017. It aimed to determine the knowledge, attitude and practice of BSE among both breast cancer and non-cancer patients, its possible relation to patient-related delay and the stage of breast cancer at diagnosis.

\section{Material and methods}

Data were collected from 270 female participants via an interviewadministered questionnaire at two institutions: Burj Alamal Breast Clinic and Alban-jadeed Hospital (ABJ) in Khartoum, Sudan. This was a case-control study of 170 breast cancer patients sampled at the breast clinic, while 100 non-cancer patients were selected randomly from the Obstetrics and Gynaecology Department at ABJ Hospital during the same time period.

\section{Results and discussion}

The mean age of breast cancer patients was 47.7 (standard deviation (SD) 13.0) years, representing $63 \%$ of our study population. The remaining $37 \%$ were non-cancer patients with an average age of 34.7 (SD 12.4) years.

Approximately $60 \%$ of our study participants were not aware of BSE and $70 \%$ did not know the signs and symptoms of breast cancer. When asked about the usefulness of BSE, 58.8\% (cancer) and 68\% (non-cancer) of our respondents replied positively. Regular BSE practice was found to be at 7.1\% and $8 \%$ among cases and controls respectively (Fig 1).

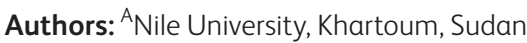

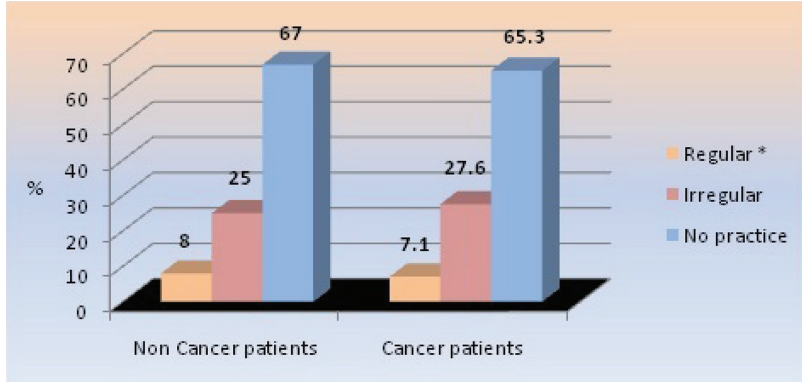

Fig 1. Breast cancer and non-cancer patients by breast self-examination practice. ${ }^{*}=$ once every month.

More than half of the breast cancer patients (54\%) presented with advanced stage disease. BSE practice was found to be associated with reduced patient-related delays in diagnosis. Those who did not practise BSE took longer to recognise $(p=0.000)$, become aware $(p=0.001)$ and seek medical help $(\mathrm{p}=0.01)$ for their breast lump than those who practised regularly (Fig 2).

No correlation was found between BSE and early stage breast cancer $(\mathrm{p}=0.619)$.

\section{Conclusion}

The prevalence of BSE practice among women in Khartoum from our sample study was inadequate at $8 \%$ and $7.1 \%$ for

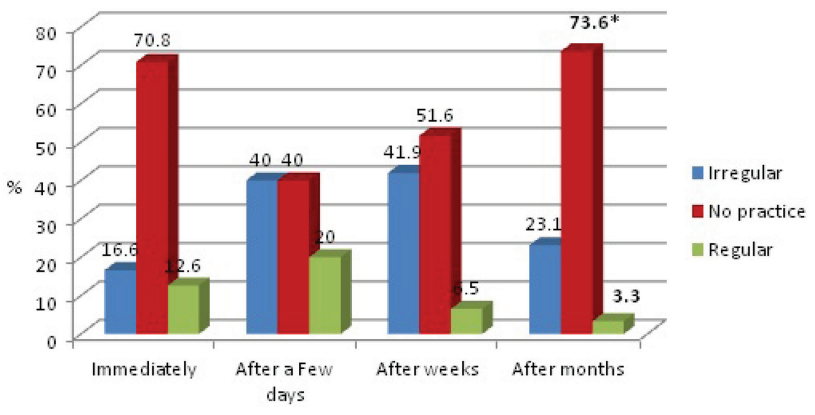

Fig 2. Relation between breast self-examination and behavioural delay. * = behavioural delay: the time from becoming aware of a breast illness to deciding to seek help. 
non-cancer and cancer patients respectively, as was their level of knowledge. However, their attitude was positive. We also found that regular BSE may play a critical role in:

$>$ increasing the awareness and perceived susceptibility to breast cancer

$>$ enhancing decision-making and motivation to seek help.

\section{Conflicts of interest}

None declared.

\section{References}

1 World Health Organization. Cancer. WHO, 2017. www.who.int/ news-room/fact-sheets/detail/cancer[Accessed 23 April 2017].
2 Cancer Registry Centre, Federal Ministry of Health, Khartoum, Sudan [Accessed 19 April 2017].

3 World Health Organization. Towards a strategy for cancer control in the East Mediterranean Region. Geneva: WHO, 2009:18.

4 Johns Hopkins Medicine. Breast self-exams. The Johns Hopkins University. www.hopkinsmedicine.org/breast_center/treatments_ services/breast_cancer_screening/breast_self_exam.html [Accessed 20 April 2017].

5 Allen TL, Van Groningen BJ, Barksdale DJ, McCarthy R. The breast self-examination controversy: what providers and patients should know? J Nurse Pract 2010;6:444-51. 